\title{
REVIEW
}

\section{Assessment of exposure to environmental tobacco smoke}

\author{
M.S. Jaakkola*, J.J.K. Jaakkola**
}

Assessment of exposure to environmental tobacco smoke. M.S. Jaakkola, J.J.K. Jaakkola. (C) ERS Journals Ltd 1997.

ABSTRACT: We present a theoretical framework for assessment of exposure to environmental tobacco smoke (ETS), and review current methods in order to provide guidelines for different types of studies. Exposure assessment should include both a quantitative dimension and consideration of time-specificity of exposure.

The ultimate aim is to measure the concentrations of ETS encountered by an individual for different time periods in various microenvironments. The first step is to identify an indicator of ETS. Personal monitoring of air nicotine and respirable suspended particulates (RSPs) are the most direct assessment methods. Indirect assessment methods include stationary measurements of tobacco smoke constituents in different microenvironments and/or questionnaire-derived information, modelled with time-activity information. Biomarkers, such as nicotine and/or cotinine in body fluids or hair, can be used as surrogate measures of dose, although they are usually affected by individual processes in the body after exposure.

The best approach to assess ETS exposure will depend on the aim of the study, the health outcome, and the resources. Personal monitoring of nicotine or RSPs is the best method in studies of short-term health effects with small study samples. Stationary measurements of indoor air nicotine or RSPs are suitable for overall monitoring of ETS in different microenvironments over time. Questionnaires and interviews are suitable when studying health outcomes with a long latency period and rare diseases requiring large study populations. Cotinine in body fluids and nicotine concentration in hair can be used to assess cumulative exposure over days or months, respectively. A combination of different methods is often the best approach.

Eur Respir J 1997; 10: 2384-2397.

Since the early 1980s, there has been growing concern about potential adverse health effects related to exposure to environmental tobacco smoke (ETS). Evidence has accumulated on ill-health associated with ETS, and such exposure has now been documented among children and adults in many countries [1-8]. A major difficulty in studying the ill-health effects of ETS has been assessing exposure, since this may occur in multiple settings with highly variable concentrations and exposure profiles may vary considerably during different age periods. Accurate and precise exposure assessment is crucial, since health effects of ETS are likely to be relatively small in magnitude. Appropriate exposure assessment is also needed for inferring causality and for risk assessment. In addition, exposure assessment is obviously necessary for development of preventive strategies.

The purpose of this paper is to present a theoretical framework for assessment of exposure to ETS, and to review current methods of exposure assessment in order to provide guidelines for choice of appropriate methods for different types of study. General definitions and concepts of exposure and its assessment will be presented, followed by definitions and components of ETS. The principles for assessment of ETS exposure will then be presented. Current methods of assessment will be reviewed in terms of their advantages and disadvantages, followed by a very brief summary of the ill-health effects of ETS. This allows the criteria for selection of the
*Finnish Institute of Occupational Health, Helsinki, Finland. **Harvard University, School of Public Health, Boston, MA, USA.

Correspondence: M.S. Jaakkola

Finnish Institute of Occupational Health Topeliuksenkatu 41 aA, FIN-00250 Helsinki Finland

Keywords: Biomarkers exposure assessment personal monitoring questionnaires tobacco smoke

Received: January 71997 Accepted after revision April 241997 appropriate method of assessing ETS exposure to be set in context, and to be formulated as user guidelines.

\section{Definitions of concentration, exposure and dose}

\section{Concentration}

Concentration is the amount of a contaminant at a particular location in a particular medium [9]. For example, for an air pollutant it is the amount of the material contained in a specified volume of air. Air pollutant concentrations are usually expressed as mass per unit volume, e.g. $\mu \mathrm{g} \cdot \mathrm{m}^{-3}$, and gaseous pollutants may also be expressed as a mixing ratio with air, e.g. parts per million (ppm) by volume. Air pollutant concentrations vary in time and space.

\section{Exposure}

Exposure is defined as the contact of pollutant with a susceptible surface of the human body [9-11]. For ETS, this means contact with the eyes, the epithelium of the nose, mouth and throat, and the lining of the airways and alveoli. With respect to time, there are a number of possible formulations, including instantaneous exposure, peak exposure, average exposure over a specified time period, and cumulative exposure [11]. 
Dose

Dose is defined as the amount of contaminant that crosses a boundary of the body $[9,10,12]$. Dose varies with the exposure concentration, the time course of exposure, and with the physiological state of the individual, including breathing pattern [9]. If the pollutant is absorbed, for example across the lung epithelium into the blood, the amount absorbed is the dose to the body, and the pollutant that reaches the target organ of toxic action is the biologically effective dose [9].

\section{Assessment of exposure}

According to the definition presented, exposure to a pollutant implies the simultaneous presence of a person and the pollutant at a particular location and at a specified time. In the assessment of exposure, several aspects of exposure profile should be considered. Table 1 summarizes the relevant aspects that should be considered in the assessment of exposure to airborne pollutants.

\section{Quantitative assessment of exposure}

Quantitative assessment of exposure should include the magnitude of the pollutant concentration in a specified environment, the duration of exposure, and the time pattern of exposure [9].

Magnitude of the pollutant concentration. This is determined by the number and type of pollution sources in a given environment and by the characteristics of the environment. For air pollutants, important characteristics include the volume of the polluted space, the rate of air change and other factors affecting removal. The relevant concentration for an individual's exposure to a pollutant is the concentration in the breathing zone of the person, which is also determined by the proximity of the person to the pollution source.

Duration of exposure. This is the time period during which a person is exposed to the pollutant in a specified microenvironment. A microenvironment refers to "a three-dimensional space with a volume in which contaminant concentration is spatially uniform during some specific time interval" [12]

Table 1. - Relevant issues of exposure profile to be considered in assessment of exposure to air pollutants

\section{Quantitative assessment of exposure}

Magnitude of the pollutant concentration in a specified microenvironment

Duration of exposure in a specified microenvironment

Time pattern of exposure

Variable pollutant concentrations encountered by an

individual as he/she moves through time and space

\section{Time-specificity of exposure}

Time period or latency period from exposure to the manifestation of the health outcome of interest

Relevant exposure-time profile

Peak exposure concentration, average exposure, or cumulative exposure

Susceptible age period or maturation phase

Calendar time
Time pattern of exposure. This characterizes the exposure over time experienced by an individual who moves through time and space and encounters highly variable pollutant concentrations.

\section{Time-specificity of exposure}

Important aspects of exposure assessment are related to time-specificity of exposure. The critical question is: what is the biologically relevant exposure? This varies according to the pollutant and the health outcome of interest. Time-specificity of exposure is a complex issue, because several dimensions should be considered.

Time period or latency period from exposure to the manifestation of the health outcome. Development of different health outcomes requires variable time periods after exposure has taken place. Potential health effects of pollutants range from acute transient sensory and irritant effects through short-term physiological reactions to severe long-term diseases [13]. For example, exposure to ETS may cause acute exacerbation of asthma or development of lung cancer detected 10-20 yrs later.

Exposure-time profile. Different health outcomes are related to different time profiles of exposure. For example, respiratory symptoms may be related to repeated high peak exposure levels, while development of lung cancer may require cumulative exposure over long time periods. Failure to recognize the relevant time profile of exposure may lead to false-negative findings or to biased estimates of effects.

Age period or maturation phase. For some health outcomes, the biologically relevant exposure is that which takes place during a susceptible age period or a susceptible phase of maturation. For example, exposure taking place during a critical developmental phase of the foetus can cause birth malformations, whereas similar exposure at a later stage may have no serious effects.

Calendar time. When assessing health effects of pollutants on populations, the relevant exposure may be that taking place over a certain calendar time period. Such information is often needed for risk management purposes.

\section{Prospective versus retrospective assessment of exposure}

Exposure assessment can be made prospectively or retrospectively, with important implications for validity issues. Prospective assessment takes place before the manifestation of the health outcome. This is usually preferable, since potential misclassification of exposure by prospective assessment is likely to be nondifferential rather than differential. Unfortunately, prospective assessment is often unfeasible, especially for diseases with a long latency period.

Retrospective exposure assessment takes place after the manifestation of the health outcome. This type of assessment is more likely to present problems regarding the validity and precision of exposure estimates. Differential misclassification is the major validity concern. Recall bias may be a problem in retrospective assessment: diseased subjects (or their surrogates) may be more prone to recall exposure than nondiseased ones. 
Precision of exposure assessment is dependent on how well the actual exposure can be reconstructed from the information available at the time of assessment. Factors such as available information on the distributions and strength of exposure sources, measurements of pollutant concentrations, and information on activity patterns of the subjects affect the precision of exposure estimates. The potential impacts of different types of exposure misclassification on health effect estimates are discussed later, in the context of validity issues.

\section{Definitions and components of environmental tobacco smoke}

Exposure to ETS is defined as the exposure of a person to tobacco combustion products from smoking by others [14]. Passive smoking and involuntary smoking are synonymous terms. Exposure to ETS is also used to describe exposure of a foetus to tobacco combustion products and/or their metabolites from an actively or passively smoking mother [2].

Tobacco smoke contains over 4,500 compounds found in both vapour and particle phases. These compounds include five known human carcinogens, 10 probable human carcinogens, three animal carcinogens and many toxic agents, such as carbon monoxide, ammonia, acrolein, acetone, nicotine and nitrogen oxides [6]. Tobacco smoke also contains respirable suspended particulates, which contain dicyclic and polycyclic aromatic hydrocarbons, some of which are known animal carcinogens.

Mainstream smoke is tobacco smoke generated during puff-drawing in the burning cone of a tobacco product, which is inhaled directly by the smoker before it is released into the surrounding air [2]. Sidestream smoke is defined as a combination of: 1) smoke emitted into the air during burning of a tobacco product between puffs; 2) smoke escaping into the surrounding air during puffs; and 3) smoke components that diffuse through cigarette paper [2]. ETS is composed of sidestream smoke and exhaled mainstream smoke, the former contributing to nearly all of the vapour-phase constituents and over half of the particulate matter [6]. Mainstream and sidestream smoke are qualitatively similar in chemical composition, but due to differences in the burning conditions the quantities of constituents are different. The cigarette burns at a higher temperature during inhalation, leading to more complete combustion in mainstream smoke. Thus, sidestream smoke contains considerably higher concentrations of many carcinogenic and toxic substances than the mainstream smoke; for example, the five known and the 10 probable human carcinogens are enriched in the sidestream smoke; table 2 presents the ratios of sidestream smoke to mainstream smoke emissions of selected compounds from filterless cigarettes. A filtered cigarette can produce substantially reduced mainstream smoke emissions compared to filterless cigarettes, while the sidestream smoke emissions show little variability between the two types [6].

\section{Assessment of exposure to ETS}

The basic aim in the assessment of exposure to ETS is to measure the concentrations of ETS encountered by an individual for different time periods as he/she moves through various microenvironments, such as home, workplace and public places. Figure 1 illustrates the concepts of exposure assessment by an example of ETS exposure in an office worker. The ordinate shows the concentrations that the individual encounters in different microenvironments, indicated by $\mathrm{m}_{1}, \mathrm{~m}_{2}$, etc. The abscissa shows the time that the individual spends in each microenvironment, indicated by $\mathrm{t}_{1}, \mathrm{t}_{2}$, etc. In the morning, for example, the individual is exposed to smoking by her husband at the breakfast table, shown by $\mathrm{m}_{1}$ and $t_{1}$. She then takes a bus to work and encounters little exposure $\left(\mathrm{m}_{2}, \mathrm{t}_{2}\right)$. In the workplace, she is exposed to smoking by colleagues $\left(\mathrm{m}_{3}, \mathrm{t}_{3}\right)$. She takes lunch at a restaurant, where the ETS concentration is high $\left(\mathrm{m}_{4}, \mathrm{t}_{4}\right)$.

Table 2. - Emissions of selected tobacco smoke constituents in fresh, undiluted mainstream smoke (MS) and diluted sidestream smoke (SS) from unfiltered cigarettes according to the US Environmental Protection Agency (EPA) report [6]

\begin{tabular}{lcc}
\hline Constituent & Emissions in MS & SS/MS ratio \\
\hline Known human carcinogens & & \\
Benzene & $12-48 \mu \mathrm{g}$ & $5-10$ \\
2-Naphthylamine & $1.7 \mathrm{ng}$ & 30 \\
4-Aminobiphenyl & $4.6 \mathrm{ng}$ & 31 \\
Nickel & $20-80 \mathrm{ng}$ & $13-30$ \\
Polonium-210 & $0.04-0.1 \mathrm{pCi}$ & $1-4$ \\
Probable human carcinogens & & \\
Formaldehyde & $70-100 \mu \mathrm{g}$ & $0.1-50$ \\
Hydrazine & $32 \mathrm{ng}$ & 3 \\
$N$-Nitrosodimethylamine & $10-40 \mathrm{ng}$ & $20-100$ \\
$N$-Nitrosodiethylamine & $\mathrm{ND}-25 \mathrm{ng}$ & $<40$ \\
$N$-Nitrosopyrrolidine & $6-30 \mathrm{ng}$ & $6-30$ \\
1,3-Butadiene & $69.2 \mu \mathrm{g}$ & $3-6$ \\
Aniline & $360 \mathrm{ng}$ & 30 \\
Benzo[a]pyrene & $20-40 \mathrm{ng}$ & $2.5-3.5$ \\
$N$-Nitrosodiethanolamine & $20-70 \mathrm{ng}$ & 1.2 \\
Cadmium & $110 \mathrm{ng}$ & 7.2 \\
Toxic substances & & \\
Carbon monoxide & $10-23 \mathrm{mg}$ & $2.5-4.7$ \\
Acrolein & $60-100 \mu \mathrm{g}$ & $8-15$ \\
Ammonia & $50-130 \mu \mathrm{g}$ & $3.7-5.1$ \\
Nitrogen oxides & $100-600 \mu \mathrm{g}$ & $4-10$ \\
\hline PCi picocure &
\end{tabular}

PCi: picocurie ( 1 Curie $=3.7 \times 10^{10}$ Becquerel $)$; ND: nondetectable.

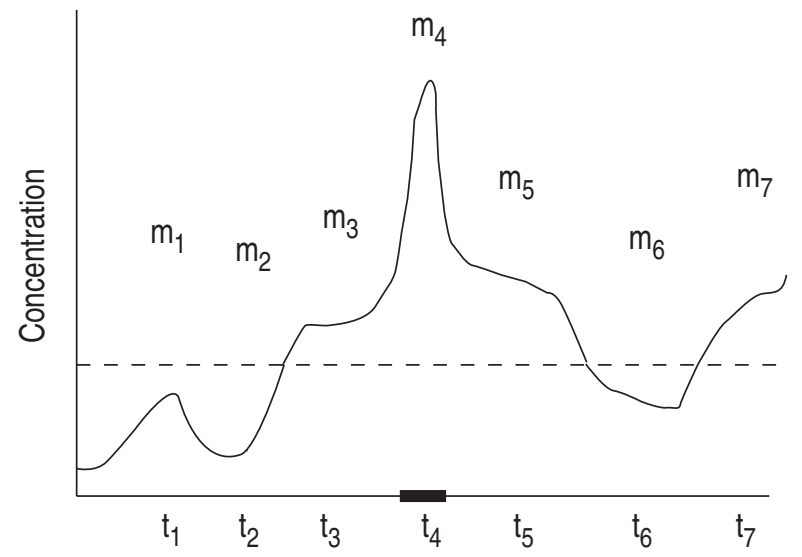

Fig. 1. - An example of environmental tobacco smoke (ETS) exposure of an office worker. The ordinate shows the concentrations that the person encounters in a number (i) of different microenvironments $\left(\mathrm{m}_{\mathrm{i}}\right)$. The abscissa shows time periods that the person spends in each microenvironment $\left(t_{j}\right)$. _._. : mean concentration. For further explanation see text. 
Afterwards she is again exposed to smoking at work $\left(\mathrm{m}_{5}, \mathrm{t}_{5}\right)$. Later, she encounters relatively low ETS levels, while shopping $\left(\mathrm{m}_{6}, \mathrm{t}_{6}\right)$, and somewhat higher levels at home due to spouse smoking $\left(\mathrm{m}_{7}, \mathrm{t}_{7}\right)$.

Depending on the objective of the study, the exposure of interest may be the mean ETS concentration, indicated by the horizontal line in figure 1 , or the cumulative exposure, indicated by the area under the concentration-time curve. Time-specific exposure assessment can be made by measuring the concentrations that the person encountered during a specified time period, for example time period $t_{4}$, indicated by the bold line on figure 1. This framework forms the basis for different methods of ETS exposure assessment, discussed later.

Since environmental tobacco smoke is a complex mixture of gases and particulate matter, ETS exposure is in reality composed of numerous concentration-time curves of different compounds. Relatively little is known about the importance of individual constituents in causing adverse health effects, and interactions between different compounds may also play an important role. Thus, assessment of exposure to the entire ETS mixture is relevant. The first step in exposure assessment is to identify an indicator (or a marker) of ETS, that can be measured and that represents the magnitude, duration and frequency of ETS exposure [6]. It is more feasible to measure one indicator compound, than several or all compounds. Further, by selecting a good indicator, it is possible to assess overall exposure to the complex mixture. An indicator may be a chemical compound measured in the air, a variable derived from questionnaire responses, a metabolite measured in biological specimens, or an estimate derived by modelling $[6,15]$. Ideally, an indicator of ETS should vary with the source strength, and be easily and accurately measured at an affordable cost. If it is a chemical compound in the air or a biomarker, it should be unique to tobacco smoke, be easily detectable in air or biological specimens at low concentrations, and should occur in a consistent ratio to other components of ETS that are related to health concerns [16].

In this paper, direct and indirect methods of ETS exposure assessment are introduced. The strengths and limitations of these methods are discussed in relation to the requirements set for an ideal indicator, as well as in relation to validity issues.

\section{Validity issues}

Any assessment method of exposure to ETS should be valid (i.e. accurate), and therefore not influenced by systematic errors. Such a method should also be reliable (i.e. precise), so that the random error affecting the estimates is within acceptable limits.

Measurement validity is defined as the degree to which a measurement measures the phenomenon that it purports to measure [17]. Validation of ETS exposure assessment methods is problematical, since there is no gold standard. The validation is, thus, based on comparing results obtained with one method to those obtained with the other "nonideal" methods [18]. Measurement validity comprises three dimensions $[17,19]$.

1) Content validity describes the extent to which the measurement incorporates the domain of the phenome- non under study. For example, assessment of ETS exposure should include all important microenvironments where exposure takes place.

2) Criterion validity describes the extent to which the measurement correlates with the phenomenon being studied. For example, questionnaire-derived assessment of ETS exposure could be compared with personal monitoring of an indicator compound in the air, but, as mentioned above, no gold standard method is available for ETS.

3) Construct validity describes the extent to which the measurement corresponds to the theoretical concepts or constructs concerning the phenomenon under study. For example, when assessing ETS exposure, the relevant time period is dependent on the mechanisms underlying the health outcome of interest.

Reliability of exposure assessment refers to the stability of the measurement results and is tested by examining repeatability of the results. Reliability encompasses the nonsystematic, random variation observed upon repeated measurements $[17,19]$.

Measurement error or misclassification of ETS exposure can be nondifferential, i.e. it is not related to the health outcome status. This type of misclassification leads to an imprecise estimate of exposure, which generally leads to an underestimation of any true effect of exposure on health. Such misclassification will, thus, reduce the sensitivity of the study to detect small adverse effects, which is relevant to studies of ETS. In a quantitative study, a random measurement error may bias the estimate of effect per unit of exposure [20].

Misclassification can also be differential, i.e. related to the health outcome status. This type of misclassification can bias the results of a study in either direction, so that a spurious relationship may be created or an existing relationship may go undetected. Recall bias, described earlier, is a special case of differential misclassification. Another type of information bias is caused by more complete assessment of exposure in the diseased than in the nondiseased subjects.

\section{Direct assessment methods}

Figure 2 shows a diagram of the chain of elements leading to exposure of an individual and finally to a biologically effective dose. ETS is produced by the sources, that is smokers, present in the same space as the individual. The source strength is determined by the number of smokers and their smoking pattern. Environmental factors, including the volume of the polluted space, the ventilation system, and other factors affecting removal of ETS, modify the concentration of ETS encountered in a given environment. In addition to the concentration of ETS, the uptake depends on breathing rate, mouth versus nose breathing, airway geometry and other respiratory factors, and, thus, modifies the dose received by the human body. The biologically effective dose is determined by individual processes taking place after uptake, including metabolism and elimination of the compound. For some health effects, such as irritation of mucous membranes, the dose received by the body is very similar to the biologically effective dose, but for other effects, such as cancer, individual metabolism and elimination greatly influence the biologically effective 


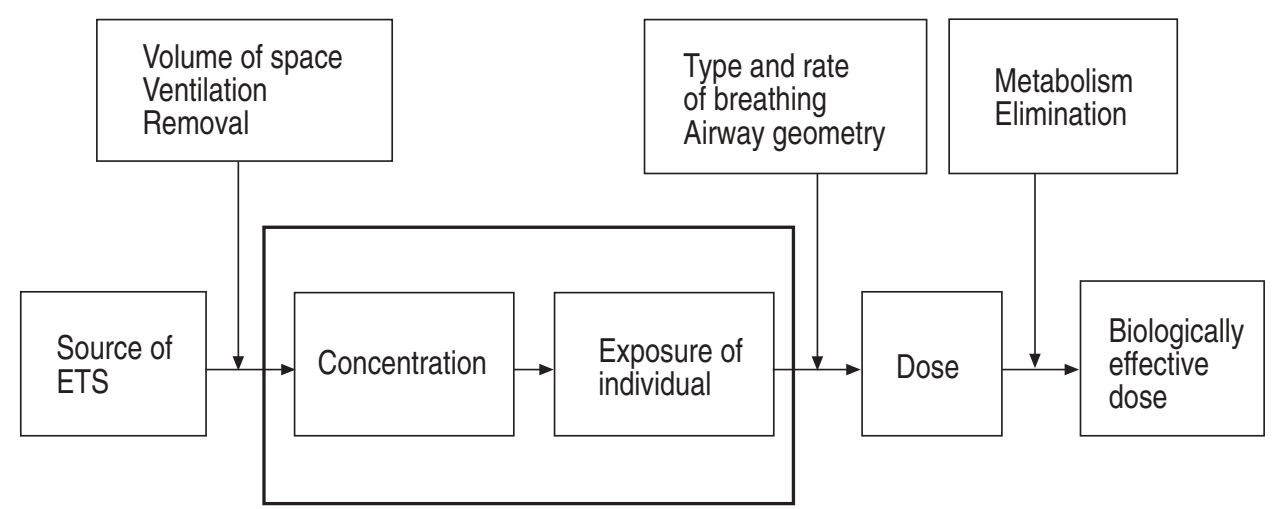

Fig. 2. - The chain of elements that lead to exposure of an individual to environmental tobacco smoke (ETS) and the factors that determine the resulting dose to the human body and the biologically effective dose. Different environmental and intrinsic factors that influence or modify exposure and dose are illustrated.

dose. Figure 2 illustrates exposure in a given microenvironment. The total exposure of an individual is determined by concentrations of ETS and time intervals spent at different microenvironments.

Personal monitoring. Personal monitoring of relevant tobacco smoke components can be considered as the most direct method to assess ETS exposure. Personal monitoring measures the contact of an individual with different concentrations of a pollutant in the course of his/her normal activities, using samplers worn for several hours to several days [12]. Personal monitoring usually measures an integrated exposure across a variety of environments occupied by the person over time. Continuously recording instrumentation with data-logging capacity has also been developed [9, 21]. The samplers can be passive, working on the principle of diffusion, or active pumps, collecting and concentrating the air contaminant for further analysis or drawing air through a direct-reading detector $[6,12]$.

Limitations of personal monitoring methods to assess ETS exposure include the following: 1) they can only be used for relatively short time periods; 2) the time period during which monitoring is carried out may not be representative of an individual's normal activities in the long run; 3) they are presently not available for all components of ETS related to health concern; and 4) they are time-consuming and expensive, and thus, may, not be feasible in studies with large samples.

Vapour-phase nicotine and respirable suspended particulates. Vapour-phase nicotine and respirable suspended particulates (RSPs) are the most commonly measured indoor air indicators of ETS, although personal monitoring equipment is available also for some other components of tobacco smoke, such as carbon monoxide, nitrogen oxides and formaldehyde $[12,15]$. The advantages of nicotine and RSPs include the availability of validated and easy measurement methods, existing knowledge of their emission rates from tobacco combustion, and knowledge of their relation to other ETS components [6].

Nicotine is emitted in side-stream smoke particle phase and evaporates as it is diluted. It is suitable as an indicator of ETS, since it is specific to tobacco combustion and is emitted in large quantities in ETS [6]. Nicotine can be collected on a glass fibre backup filter treated with sodium bisulphate and analysed by gas chromatography [22-24]. A disadvantage of vapourphase nicotine as an ETS indicator is its high adsorption rate to indoor surfaces and a tendency to be reemitted even in the absence of active smoking. This property can change its concentration relative to other ETS constituents.

Respirable suspended particles are defined as particles with an aerodynamic diameter of $<10 \mu \mathrm{m}$. RSP samples can be collected on Fluoropore or Teflon filters applying cyclone or impactor separators to collect respirable particles, and the RSP sample is then assessed by gravimetric, optical or piezoelectric methods [16, 21 , $25,26]$. RSPs contain compounds that are probably responsible for adverse health effects, such as polycyclic aromatic hydrocarbons and tobacco-specific $N$ nitrosamines. A disadvantage is that RSPs are not specific for tobacco combustion, and other important indoor and outdoor sources have to be taken into account when using RSPs as an ETS indicator.

Selected examples of personal monitoring of RSP and nicotine. SPENGLer et al. [27] reported an extensive study using a personal monitoring method in the assessment of ETS-related RSP. In the study, $24 \mathrm{~h}$ personal RSP exposures were recorded with the Harvard/EPRI sampling system (Harvard School of Public Health, Boston, MA, USA) in 101 nonsmoking subjects living in two rural Tennessee communities [25, 27]. Exposure measures recorded with personal monitoring were compared with simultaneously collected home indoor and outdoor RSP concentrations. Ambient RSP pollution measurements were consistently smaller than exposures by personal monitoring by, on average, $25 \mu \mathrm{g} \cdot \mathrm{m}^{-3}$, indicating the strong influence of indoor environment on personal exposures. Correlations between home indoor RSP concentrations and personal RSP exposures were high. ETS at home was a substantial contributor to personal RSP exposure, the average personal RSP exposure being $28 \mu \mathrm{g} \cdot \mathrm{m}^{-3}$ higher in subjects exposed to ETS at home, compared to those not exposed at home. Predictive regression models including home ETS exposure explained $16-17 \%$ of the variation in personal RSP concentrations. To illustrate the importance of home ETS exposure for personal RSP exposures, figure 3 shows the cumulative frequency distributions of ambient and personal RSP concentrations of the ETS-exposed and non-ETS-exposed groups.

Coghlin et al. [28] compared indices based on questionnaire and seven-day diary of ETS exposure during 1 week with weekly nicotine levels collected with passive personal monitors in 53 nonsmoking volunteers. Based on the personal monitoring measurements, air nicotine concentrations averaged over the week ranged $0.11-11 \mu \mathrm{g} \cdot \mathrm{m}^{-3}$ with a median of $2.8 \mu \mathrm{g} \cdot \mathrm{m}^{-3}$ in the first, and $1.7 \mu \mathrm{g} \cdot \mathrm{m}^{-3}$ in the last phase of the study. Nicotine concentrations in selected social situations, such as in 


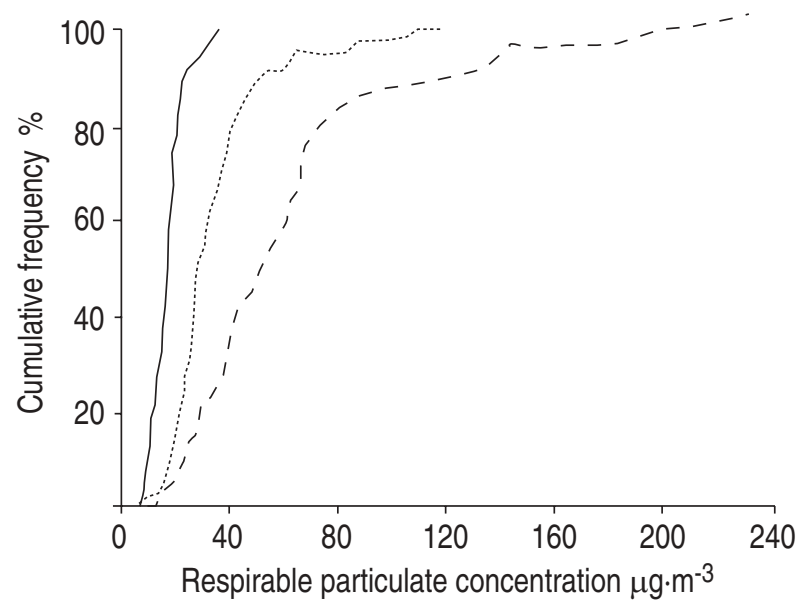

Fig. 3. - Cumulative frequency distributions of central site ambient $(-)$ and personal RSP concentrations of environmental tobacco smoke (ETS)-exposed (-.--...-...) and non-ETS-exposed (------) subjects among 101 nonsmoking adults from two rural Tennessee communities. ETS-exposed subjects lived in households with at least one smoker and non-ETS-exposed subjects lived in nonsmoking households. (Reprinted, with permission, from [27]. (C)American Chemical Society, 1985).

bars and restaurants, ranged $6-82 \mu \mathrm{g} \cdot \mathrm{m}^{-3}$. An index of ETS exposure (hsp index), summing reported exposure in all locations over 7 days and weighted according to the number of hours of exposure (h), the number of smokers present (s) and the proximity of smokers (p), provided the best correlation with nicotine levels obtained by personal monitoring. The correlation coefficient (r) was 0.910 for the questionnaire-based index and 0.948 for the diary-based index. ETS exposure index was further refined by taking into account a measure of ETS intensity in certain situations, and this index predicted closely the nicotine levels obtained by personal monitoring with an $\mathrm{r}^{2}$ of 0.98 for both the questionnairebased and diary-based indices.

\section{Indirect assessment methods}

Indirect assessment methods of ETS exposure refers here to the approach by which information is collected about: 1) concentrations of indoor air tobacco smoke constituents or ETS sources in different microenvironments; and 2) time periods spent by individuals in each microenvironment, and subsequent indirect exposure assessment made by combining the available information either with mathematical formulas or by modelling approaches. On the basis of collected data the following matrix can be formed:

\begin{tabular}{llllll} 
& $\mathrm{t} 0$ & $\mathrm{t} 1$ & $\mathrm{t} 2$ & $\mathrm{t} 3$ & $\mathrm{t} 4$ \\
\hline $\mathrm{m}_{1}$ & $\mathrm{c}_{10}$ & $\mathrm{c}_{11}$ & $\mathrm{c}_{12}$ & $\mathrm{c}_{13}$ & $\mathrm{c}_{14}$ \\
$\mathrm{~m}_{2}$ & $\mathrm{c}_{20}$ & $\mathrm{c}_{21}$ & $\mathrm{c}_{22}$ & $\mathrm{c}_{23}$ & $\mathrm{c}_{24}$ \\
$\mathrm{~m}_{3}$ & $\mathrm{c}_{30}$ & $\mathrm{c}_{31}$ & $\mathrm{c}_{32}$ & $\mathrm{c}_{33}$ & $\mathrm{c}_{34}$ \\
$\mathrm{~m}_{4}$ & $\mathrm{c}_{40}$ & $\mathrm{c}_{41}$ & $\mathrm{c}_{42}$ & $\mathrm{c}_{43}$ & $\mathrm{c}_{44}$
\end{tabular}

where $m_{i}$ refers to a number (i) of different microenvironments, for example, home, workplace, restaurant etc. The symbol $t_{j}$ refers to a number $(j)$ of time periods spent in each microenvironment, and may refer either to calendar time or a certain age period. The symbol $c_{i j}$ refers to the concentration of pollutant in each of the microenvironments at each of these times, based either on actual measurements or on estimates derived by modelling. Modelling approaches may include information on the number and strength of ETS sources in each microenvironment and on modifying environmental factors. From this matrix, total cumulative exposure of an individual (Etot) can be estimated by multiplying the pollutant concentration in each microenvironment $\left(\mathrm{c}_{\mathrm{ij}}\right)$ by the time spent in that environment $\left(\mathrm{t}_{\mathrm{ij}}\right)$ and summing the time-weighted concentrations, as indicated by the following formula:

$$
\text { Etot }=\Sigma \mathrm{c}_{\mathrm{ij}} \times \mathrm{t}_{\mathrm{ij}}
$$

Time-specific exposure can be estimated in a similar way by focusing on relevant time periods instead of total exposure, for example by calculating cumulative exposure during a specified age period.

Stationary measurements. Several components of tobacco smoke have been measured in indoor air as potential indicators of ETS, including nicotine, carbon monoxide, nitrogen dioxide, aromatic hydrocarbons, aldehydes, acrolein, acetone, benzene, toluene, $N$-nitrosamines, and RSP [6]. If concentrations of a specified tobacco smoke component are measured in all microenvironments occupied by an individual and this information is combined with detailed time-activity information to assess total exposure of that individual, the stationary monitoring method approaches direct personal monitoring of exposure. However, more often data is available on mean concentrations of compounds in different types of microenvironments and this information is then combined with individual time-activity data to provide an indirect estimate of the individual's exposure.

Concentrations of ETS constituents vary between indoor locations and over time. Factors that influence or modify indoor concentrations of ETS constituents include: 1 ) the number of smokers and their smoking pattern; 2) the volume of the space; 3 ) the ventilation or infiltration rate of the indoor space; 4) the concentration of the contaminant in the ventilation or infiltration air; 5) air mixing in the space; 6) removal of contaminant by surfaces or chemical reactions; 7) re-emission of contaminant by surfaces; and 8) the effectiveness of any air cleaners that may be present $[6,16]$. Limitations of stationary measurement methods include: 1) indoor and outdoor sources of contaminants, other than combustion of tobacco, leading to low specificity; 2) difficulties in measuring low concentrations of pollutants, leading to low sensitivity; 3 ) the fact that only relatively short time periods can be monitored; and 4) high cost of measurements.

Vapour-phase nicotine and RSP. Vapour-phase nicotine and RSP are again the most commonly used indicators of the presence and concentration of ETS [6]. At present there are a number of validated and inexpensive active monitoring methods for indoor air nicotine and $\mathrm{RSP}$, and for nicotine there are also passive monitoring methods. The advantages and limitations of using these compounds in the assessment of ETS exposure have already been discussed in the context of personal monitoring.

Selected studies of indoor air nicotine and RSP. Chamber studies have demonstrated that indoor air nicotine 
and RSP concentrations vary with the ETS source strength, and measurements in field studies have shown that their residential concentrations correlate highly with the reported amount of smoking [29-32]. For example, LEADERER and HAMMOND [30] reported a field study of 96 residences in Onondaga and Suffolk Counties in New York State, USA, where indoor air vapour-phase nicotine and RSP were monitored over a period of 1 week. Weekly nicotine and RSP indoor levels were shown to be related in a linear fashion with the reported number of cigarettes smoked in the house during that period, as shown in figure 4. The ratio of RSP: nicotine was around 11, which was in accordance with other field studies yielding estimates ranging 9-10 [33, 34]. Vapour-phase nicotine was thus judged to be a good predictor for ETS-related RSP. The impact of smoking on indoor RSP levels was pronounced in the study, since residences reporting smoking had RSP levels on average three times those measured in residences that reported no smoking (44 versus $\left.15 \mu \mathrm{g} \cdot \mathrm{m}^{-3}\right)$.

Questionnaires and interviews. Questionnaires and interviews are the most commonly used exposure assessment method in studies of health effects of ETS. Information on ETS sources and time-activity patterns of individuals can be used to assess exposure indirectly, utilizing modelling approaches. There are several advantages in the use of questionnaires, which have contributed to their position as the assessment method of choice. These include the following: 1) questionnaires can provide detailed information on ETS source strength; 2) they can provide exposure information retrospectively, when it is no longer possible to make measurements of air pollutant concentrations or biomarkers; 3 ) they can provide information on long-term exposure, which is relevant for many health effects; 4) they can provide simultaneous information on time-activity pattern and modifying environmental factors; 5) they can provide information on possible confounders in studies of health effects; 6) they are the least expensive method to obtain information on ETS exposure and are, thus, suitable for studies with large sample sizes. On the other hand, there are also many concerns associated with questionnaire assessment, including: 1) lack of a gold standard with which to validate questionnaires; 2) lack of commonly accepted standardized questionnaires; and 3 ) the possibility of misclassification of exposure for several reasons [6]. Misclassification may result from the respondents' failure to recall exposure precisely, intentional false reporting of exposure, and biased recall. The first results in nondifferential misclassification of exposure and leads to an underestimation of any true health effect. The other two factors lead to differential misclassification of exposure, which can bias the estimates of health effects either away from or towards the null. In retrospective studies, recall bias could lead to an overestimation of any true effect of ETS or even to the creation of a spurious relation, if diseased subjects are more prone to recall exposure than nondiseased ones. Recall bias has become a more pertinent issue during recent years, since the public awareness of adverse health effects related to ETS has increased. In addition, failure of the questions to elicit relevant information on exposure, and the potential effect of the interviewer's
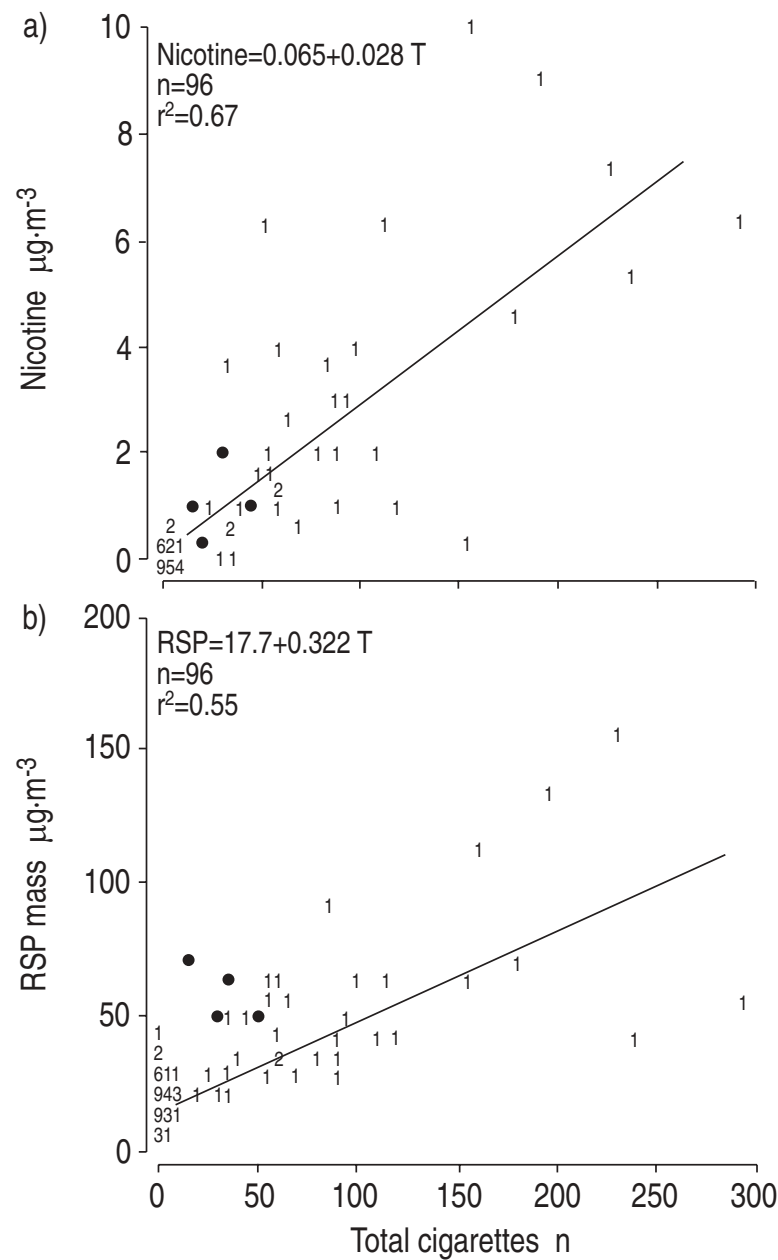

Fig. 4. - a) One-week vapour phase nicotine concentrations and b) one-week respirable suspended particle (RSP) concentrations measured in the main living area of 96 residences versus the number of questionnaire-reported cigarettes smoked during the air sampling period. Numbers 1-9 refer to the number of observations at the same concentrations. Closed circles indicate that cigar or pipe smoking was reported. Data from residences in Onondaga and Suffolk Counties in New York State. T: total number of cigarettes. (Reprinted, with permission, from [30]. (C)American Chemical Society, 1991).

knowledge of disease status on interpretation of results or on completeness of exposure assessment may also result in misclassification of exposure.

Validation of questionnaires. Different strategies have been used in an attempt to validate questionnaires for ETS exposure assessment, but as mentioned above, there is no gold standard. Personal monitoring and stationary measurements of indoor air contaminants, and measurements of cotinine in body fluids only reflects relatively short-term ETS exposure, which may differ considerably from the subject's usual long-term exposure. In addition, cotinine in body fluids also reflects processes that have taken place in the body after exposure, as will be discussed later. Despite these problems, residential indoor air levels and personal monitoring of nicotine and RSP have shown good agreement with questionnaire-reported intensity of smoking in the environment in several studies [28-30, 32, 35]. In the study by LEADERER and HAMMOND [30], which examined residential indoor air nicotine and RSP levels over a week in relation to questionnaire responses on the amount of 
smoking, the reported source intensity proved to be the dominating contributor to indoor nicotine and RSP concentrations. Only a very small additional variation in these concentrations was attributable to other factors, such as the house volume and infiltration rate. On the other hand, $28 \%$ of the residences reporting household smoking had no detectable levels of indoor nicotine, while nicotine was measured in $13 \%$ of the residences reporting no smoking. It should be noted that the location of smoking was not asked, which could increase misclassification, for example if smoking took place only outdoors. EMERSON et al. [32] assessed construct validity of ETS exposure assessment, which was based on parental reporting among asthmatic children. They formed a number of a priori hypotheses concerning relation between ETS exposure and positive, negative or null effects, and studied how many of these relation were actually found in the data in the expected direction. Approximately $80 \%$ of the hypothesized relatio were confirmed by the data.

Questionnaire-derived measures of the amount of ETS exposure have shown only moderate correlations with body fluid cotinine concentrations [3, 7, 36, 37]. In studies among adults, no more than $29 \%$ of the variance in cotinine levels could be explained by questionnaire-based multivariate approaches, while among children, parental smoking explained up to $44 \%$ of the variance in salivary cotinine concentrations [3, 7, 36-38]. In a recent study by O'CONNOR et al. [39], three methods to measure ETS exposure were compared in 415 pregnant women: personal monitoring of air nicotine, urine cotinine, and questionnaire. Women reporting ETS exposure had significantly higher levels of air nicotine exposure compared with women reporting no exposure, whereas urine cotinine did not differ between these groups. Agreement was deemed fair $($ Kappa $=0.29)$ between self-reported exposure and personal monitoring of air nicotine, but poor between urine cotinine and both selfreport $($ Kappa $=0.08)$ and air monitoring $($ Kappa $=0.10)$. In summary, studies seem to indicate that questionnairereported exposure shows better agreement with air pollutant concentration measurements than with cotinine concentrations. Hair nicotine is a relatively new biomarker reflecting exposure over a longer time period, and will be discussed in more detail later. Recently, significant quantitative relationships were shown between questionnaire-reported ETS exposure and hair nicotine concentrations in children and nonsmoking mothers [40]. However, a large variation was detected in hair nicotine concentrations among children with similar maternal and/ or paternal smoking habits. Under-reporting of parental smoking, and differences in building ventilation, exposure times and distance from the source, as well as potential differences in hair nicotine uptake, were suggested as possible explanations for the observed variation.

Reliability of questionnaire assessment. Reliability of questionnaire assessment of ETS exposure has been tested in several studies [32, 41, 42]. Coultas et al. [42] studied repeatability of questionnaire responses on lifetime ETS exposure at home on two occasions within 6 months. Adult subjects reliably report smoking by household members during their childhood, with a concordance of $>90 \%$ for parents. Concordance was $100 \%$ for reports of spouse smoking during adulthood. Also, the number of years during which household members smoked was reported reliably, but assessment of the amount of smoking was less reliable. EMERson et al. [32] explored the reliability of parent-reported ETS exposure of asthmatic children on two occasions 2 months apart among families attending four asthma clinics in San Diego, USA. The children were aged 6-17 yrs. Test-retest reliability assessments were conducted simultaneously for urine cotinine measurements in children and measurements of home indoor air nicotine during a 2 week period. Intraclass correlation coefficient was 0.86 for parent-reported use of tobacco in the home during the past week and 0.76 for parent-reported number of cigarettes to which the child was exposed at home during the past week. The correlation coefficient was also high for air monitoring results of nicotine (0.72), but was low for urine cotinine (0.04). Cummings et al. [43] compared subjects' own questionnaire reports of ETS exposure in childhood and adulthood with reports of surrogates, including parents, siblings, spouse, other household members and co-workers. A good agreement was shown between subject and surrogate reports of most ETS exposure measures, including the number of smokers in different exposure environments, the number of years exposed, and an exposure index taking into account the intensity of exposure.

Selected examples of questionnaires on ETS exposure. Questionnaires and interviews have been used frequently in studies of health effects of ETS, but the questions often provided qualitative rather than quantitative assessment of ETS exposure, such as "Do you live with a smoker?" or, "Are you exposed to ETS at work?" Such a dichotomous exposure classification leads to imprecise exposure assessment, which may cause underestimation of any true effect and thus reduce the sensitivity of the study. As discussed earlier, assessment of exposure in studies of health effects should include both quantitative assessment and consideration of the timespecificity of exposure. Recently, there have been attempts to develop standardized questionnaires allowing accurate and precise ETS exposure assessment for studies of health effects [37, 44-48].

At the Respiratory Epidemiology Unit of McGill University, we designed Questionnaires on Indoor Air Quality with the aim of providing information for both quantitative and time-specific assessment of ETS exposure [44-47]. The questionnaires included information on ETS source intensity and duration of exposure [37, 44-47]. Questions to assess ETS source intensity focused on the number of smokers in the household of the subject and their smoking rate, and on the usual smoking conditions in the workplace. Questions to assess recent exposure also covered microenvironments other than home and workplace, such as different social settings and vehicles. Information on ETS was requested for different age periods. Quantitative ETS exposure indices for different microenvironments and for different age periods were then calculated based on the collected information [37, 44-47].

In 1989, LEBOwITZ et al. [48] reported what was termed a Standard Environmental Inventory Questionnaire, developed for assessment of exposure to residential indoor 
air contaminants. The questionnaire included questions on ETS source intensity and on housing factors related to removal mechanisms of pollutants, thus allowing a quantitative exposure assessment. The questionnaire inquired about the number of cigarettes, pipefuls of tobacco and/or cigars smoked in the living quarters during the most recent weekday as well as during the most recent weekend day.

Time-activity pattern and modifying environmental factors. Questionnaires, recall interviews, and self-administered diaries have been used to determine time-activity patterns of individuals $[9,13,49,50]$. These methods can cover fixed or individually chosen time periods and categories of microenvironment $[18,48]$. Usually, a 24 $\mathrm{h}$ time-activity pattern is recorded, but the problem of the relationship between a $24 \mathrm{~h}$ pattern and a normal pattern over time has yet to be solved. Validation of this type of information is difficult. One study used a datalogger carried for 3-5 days to determine the validity of a self-completed recall diary [50]. Good agreement was found for commonly visited locations, e.g. bedroom, bathroom and workplace, but poorer agreement was found for locations visited infrequently or for short time periods, e.g. cellar and vehicle. In addition, questionnaires can provide information on environmental factors modifying ETS concentrations in different microenvironments, including the volume of the occupied space, the ventilation system, the use of any air cleaners, etc. [48]. Modelling approaches combining measured or estimated pollutant concentrations with time-activity patterns of individuals can be developed to provide an indirect assessment of total cumulative or time-specific ETS exposure.

\section{Biomarkers}

A biomarker of exposure to an air pollutant refers to an exogenous substance or its metabolite, or the product of interaction between a xenobiotic agent and some target molecule, that can be measured in a compartment within the human body, such as tissues, cells, fluids or expired air [51]. A detectable biomarker indicates that exposure to an air pollutant has taken place and that intake of a contaminant has occurred. Levels of biomarkers are affected by processes taking place in the body after exposure has occurred, including the uptake, distribution, metabolism, and elimination of the measured compound $[6,12]$. Biomarkers can thus be considered as surrogate measures of dose, rather than direct or even indirect measures of exposure. When using biomarkers in the assessment of dosimetry of exposure, it should be kept in mind that the relation between a biomarker and the exposure is complex due to the processes described. Ideally, a biomarker of ETS should: 1) be specific to tobacco combustion; 2) have a long half-life in the body; 3 ) be related in a quantitative fashion to a prior exposure regimen; 4) be either the agent associated with health effects or be strongly and consistently associated with such an agent; 5) be detectable in trace quantities with high precision; 6) be measurable in samples collected by noninvasive techniques; and 7) be inexpensive to assay $[6,15]$. In practice, an ideal biomarker of ETS has been difficult to find.
Several potential biomarkers of ETS have been explored, including carboxyhaemoglobin, thiocyanate, nicotine and cotinine, DNA adducts, and protein adducts. Thiocyanate concentrations in body fluids, carbon monoxide in expired air, and carboxyhaemoglobin are not specific and sensitive enough for ETS, although they have been useful in distinguishing active smoking from nonsmoking $[5,15]$. Nicotine and its metabolite cotinine, measured in plasma, urine or saliva, are the most widely used biomarkers of ETS, but there are also several problems related to their use. Hair nicotine content is a new biomarker with some advantages over the previous ones.

Nicotine and cotinine in body fluids. The advantages of nicotine and cotinine in body fluids as biomarkers of ETS include their relatively high sensitivity and specificity for tobacco combustion and the availability of accurate measurement methods at low concentrations [6]. However, there are many limitations related to their use, including: 1) a short half-life in the body fluids, so that they represent only very recent ETS exposure, which may be relevant for some, but not all, health outcomes of interest; 2) considerable intersubject variability due to differences in uptake, metabolism and elimination; and 3 ) the likelihood that they are not active agents in causing adverse health effects [6, 52]. The specificity of these biomarkers for tobacco smoke has recently been questioned, since plant sources other than tobacco have been identified, including plants from the Solanaceae family (e.g. tomato and potato), cauliflower and tea [53, 54]. On the other hand, contribution of dietary sources of nicotine to serum cotinine levels is estimated to be small in comparison to ETS exposure [55].

Nicotine has a very short half-life of approximately $2 \mathrm{~h}$ in the blood and is metabolized and excreted in the urine [6]. Cotinine is one of the major metabolites of nicotine. It has a somewhat longer half-life, and has largely replaced nicotine measurements in body fluids. Among adult nonsmokers exposed to ETS, the half-life of cotinine ranges $1-2$ days (7-40 h), and is somewhat longer among children, ranging 32-82 h, and even up to $160 \mathrm{~h}$ in neonates $[6,56,57]$. Cotinine can be measured in plasma, urine and saliva, and the choice of the optimal body fluid is still a controversial question [5, 58]. Cotinine can be quantified with a double antibody radioimmunoassay [56], with an enzyme-linked immunosorbent assay [59] or with gas chromatography [58, 60-62].

Selected studies of cotinine in the assessment of ETS exposure. A number of studies have examined cotinine concentrations in plasma, saliva or urine in populationbased samples of smokers, nonsmokers exposed to ETS and nonsmokers not reporting ETS exposure. Distinguishing between active and passive smoking on the basis of cotinine measurements may be difficult, and there are no generally accepted cut-off points. ETZEL [63] reviewed the available studies in 1990, with the aim of evaluating the relationship between saliva cotinine concentration and reported tobacco smoke exposure in both active and passive smokers. Cotinine concentrations were clearly highest in smokers, with an average of $318 \mathrm{ng} \cdot \mathrm{mL}^{-1}$, and higher in nonsmokers exposed 
to ETS than in unexposed nonsmokers. Based on the available data, a categorization of saliva cotinine concentrations into four groups was suggested: 1) undetectable cotinine is associated with the absence of active or passive smoking; 2) cotinine concentrations $<10 \mathrm{ng} \cdot \mathrm{mL}^{-1}$ usually result from exposure to ETS without active smoking; 3) cotinine concentrations ranging 10-100 $\mathrm{ng} \cdot \mathrm{mL}^{-1}$ usually result from infrequent active smoking or regular active smoking with low nicotine intake, but heavy passive exposure to tobacco smoke can result in levels $\geq 10 \mathrm{ng} \cdot \mathrm{mL}^{-1}$; and 4) levels $>100 \mathrm{ng} \cdot \mathrm{mL}^{-1}$ are the result of regular active smoking [63]. Detectable cotinine levels have been measured in $80-91 \%$ of the samples in different studies, and ETS exposure has been shown to take place at home, in the workplace and in a number of other settings [3, 4, 6, 7]. In addition to plasma, saliva and urine, cotinine has also been detected in cervical fluid of women exposed to ETS [64] and in semen of men reporting ETS exposure [65].

Cotinine measurements have been compared with questionnaire assessment of ETS exposure in many studies. Questionnaire-derived measures of the level of ETS exposure have been only moderately correlated with body fluid cotinine concentrations among adults, but among children the correlations have been somewhat better [3, $7,24,31,36,37,66]$. On the other hand, although cotinine levels show considerable individual variability within exposure categories, several studies have demonstrated that average cotinine levels increase with the degree of reported ETS exposure [6]. For example, among adult populations the mean urinary cotinine concentrations have been shown to increase with the degree of selfreported exposure [66], and with the number of selfreported exposures to ETS during the previous 4 days, as shown in figure 5 [3]. Among nonsmoking women in a 10-country collaborative study, urinary cotinine/creatinine levels rose with self-reported ETS exposure from no exposure through exposure at work alone and exposure only at home, to exposure both at home and at work [4]. The results of a linear regression analysis indicated that reported duration of ETS exposure and the number of cigarettes to which the subject reported being exposed were strongly related to the urinary cotinine level. Among children, salivary and urinary cotinine levels have been shown to rise with the number of smoking parents in the home [31, 38], and in infants, urinary cotinine levels increased with the number of cigarettes smoked by the mother during the previous $24 \mathrm{~h}$ [67]. Among 202 newborns, the cord serum level of cotinine was significantly linearly related to the average daily number of cigarettes smoked by the mother during pregnancy [68]. The cotinine levels measured in nonsmokers exposed to ETS have ranged from less than $1 \%$ to about $8 \%$ of the levels measured in active smokers [5, 69]. However, proportionality should not be assumed between the ratio of cotinine levels in passive and active smokers and the relative doses of other constituents of tobacco smoke.

Hair nicotine. Hair nicotine content is a relatively new biomarker of ETS. Human hair has been shown to have a high affinity for airborne nicotine. It is recommended to take the proximal $2 \mathrm{~cm}$ of hair behind the ears as the specimen, and the nicotine concentration of this rep-

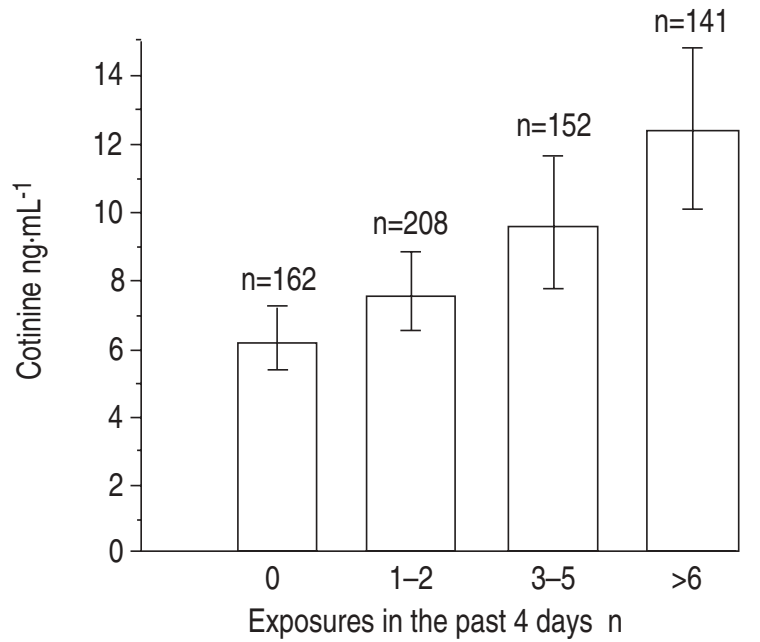

Fig. 5. - Mean urinary cotinine levels among 663 adult nonsmokers from Buffalo, New York, as a function of the number of selfreported exposures to ETS during the preceding 4 days. (Reprinted, with permission, from [3]).

resents exposure during the previous 1-2 months [70]. Hair nicotine concentration is determined by gas chromatography after a basic diethyl ether extraction procedure. Chamber studies have revealed a linear relation between the hair uptake rates of nicotine and the duration of exposure to airborne nicotine initially, but the uptake rate decreases after 4-6 weeks of exposure [71]. Adsorption of nicotine from the surrounding air seems to be the dominating contributor to the overall nicotine content found in the hair, although systemic nicotine probably contributes. Hair nicotine content has been shown to discriminate smokers from ETS-exposed nonsmokers and even between different levels of selfreported ETS exposure [40, 70].

Recently, a quantitative relation was reported between ETS exposure and the hair nicotine concentration in children and their mothers [40]. Children's hair nicotine levels were linearly related to the daily number of cigarettes smoked at home by the mother (increase of 0.8 $\mu \mathrm{g} \cdot \mathrm{g}^{-1} \cdot$ cigarette $^{-1} ; 95 \%$ confidence interval $(95 \% \mathrm{CI})$ $0.43-1.18)$ and by the father $\left(1.3 \mu \mathrm{g} \cdot \mathrm{g}^{-1} \cdot\right.$ cigarette $^{-1} ; 95 \%$ CI 0.81-1.73). The hair nicotine levels of nonsmoking mothers were linearly related to the daily number of cigarettes smoked by the father at home $\left(0.4 \mu \mathrm{g} \cdot \mathrm{g}^{-1} \cdot \mathrm{cig}-\right.$ arette $^{-1}$; 95\% CI -0.06-0.90). The hair nicotine levels in mothers were also linearly related to personal smoking, and the hair nicotine concentrations of the children of smoking mothers were approximately $25 \%$ of the concentrations measured in the mothers themselves. Figure 6 shows the mean and median hair nicotine concentrations in mothers and their children at different maternal daily smoking rates.

4-aminobiphenyl adduct of haemoglobin. The 4-aminobiphenyl adduct of haemoglobin (4-ABP adduct) is one of the protein adducts used as a biomarker of ETS. It is determined by gas chromatography-mass spectrometry [72]. Its advantages are: 1) a relatively long halflife in the body of approximately 120 days; 2) its high specificity for tobacco smoke; and 3) its likelihood to have direct adverse effect on health, since it is a known human carcinogen. In a study of 15 smoking and 40 nonsmoking pregnant women, the mean 4 -ABP adduct 
level was significantly higher in smokers compared with nonsmokers. Among nonsmokers, the 4-ABP adduct level increased significantly with increasing exposure to ETS measured with personal monitoring of air nicotine [72]. Nonsmokers exposed to ETS appear to have 10-20\% of the 4-ABP adduct levels measured in active smokers $[6,72]$. When comparing these results with the cotinine levels in passive smokers (approximately $1-8 \%$ of the concentrations in active smokers) it should be kept in mind that 4-aminobiphenyl is enriched in the sidestream smoke relative to mainstream smoke. About 31 times as much 4-ABP is emitted in sidestream smoke as in mainstream smoke (table 2), whereas only twice as much nicotine is emitted in sidestream smoke. Thus, it is necessary to be cautious in assessing exposure to ETS on the basis of biomarkers.

\section{Health effects of ETS}

A considerable amount of evidence relating ETS exposure to adverse health effects has accumulated since the 1970s [2, 5, 6, 73-79]. Some health effects are fairly well established, whereas many suggested effects require further investigation. Several of the criteria classically used to assess causality of observed relation are closely linked to the quality of exposure assessment, for example, the temporal relationship between exposure and the health outcome, the strength of the observed association and the evidence of an exposure-response gradient. Valid and precise assessment of ETS exposure is, thus, an essential part of studies of health effects.

As discussed in detail in the context of general aspects of exposure assessment, time-specificity of exposure is a complex issue, since several dimensions of time have to be taken into account. Firstly, health effects can be divided into acute and long-term effects, requiring different time periods from exposure to the manifestation of the outcome. Potential health effects of ETS may include acute transient sensory and irritant effects, short-term physiological reactions or severe long-term diseases. Secondly, different health outcomes are relat-

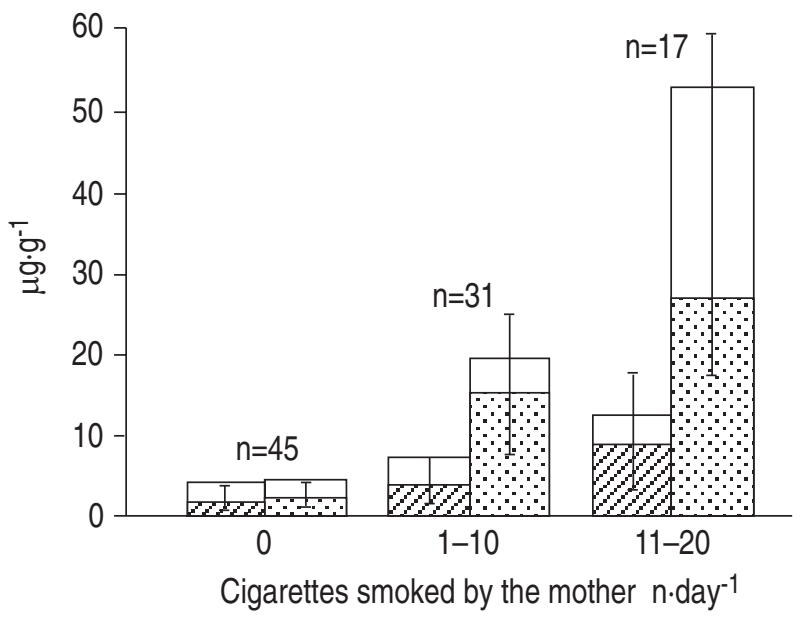

Fig. 6. - Hair nicotine concentrations in mothers ( $\because$ ) and their children ( $Q$ ) as a function of the maternal daily smoking rate, among 93 Norwegian families. The mean concentration is the higher bar, the median is the lower bar, and the 25th-75th percentile range is indicated around the median. (Reprinted, with permission, from [40]). ed to different time-profiles of exposure, ranging from transient peak values to cumulative lifetime exposure. Thirdly, different age periods are associated with different degrees of susceptibility to adverse effects.

Table 3 summarizes the current knowledge of health effects of ETS in children and adults. These effects are divided into acute (or short-term) and long-term effects, although for several outcomes the mechanisms underlying the effects are not well understood and their classification is, thus, based on an educated guess. The effects are further divided into established effects and those for which there is strong, limited or controversial evidence. This classification was decided upon by the authors on the basis of judgement in previous reviews $[2,5,6,45$, 75-79]. For some health outcomes, relevant evidence has been reported recently and, in these cases, more recent references have been included [46, 47, 80-82].

\section{Selection of the best approach to assess exposure to ETS}

A number of factors influence the selection of the best approach to assess exposure to ETS in a particular study. These include: the aim of the study; the health outcome of interest; the time-specificity of exposure; the resources available for the study; the size of the study population; and the motivation of the subjects to participate. The type of exposure assessment needed for public health studies aiming at description of distributions of exposure in populations over time, differs from that required for health effect studies focusing on specific relations between ETS exposure and different health

Table 3. - Health effects of environmental tobacco smoke

\section{Acute or short-term}

Established

Irritation of the eyes, nose, throat and lower respiratory tract $[2,6,76]$

Exacerbation of asthma [2, 6]

Increased lower respiratory infections in children $[2,6,76]$

Strong evidence

Increased upper respiratory tract infections in children

$[2,6,76]$

Increased risk of angina in coronary heart disease patients [77, 78]

Limited or controversial evidence

Acute reduction in lung function in adults [2]

Increased risk of episodes of phlegm in adults [80]

Long-term

Established

Increased chronic respiratory symptoms in children $[2,6]$ Increased lung cancer risk in nonsmoking adults $[2,6,75$, 76]

Reduced birth weight (mother's personal smoking) [79]

Strong evidence

Reduced lung growth in children $[2,6,45]$

Increased risk for new asthma in children $[6,81]$

Increased otitis media and middle ear effusion in children $[2,6]$

Increased respiratory symptoms in adults $[6,47,82]$

Increased risk for cardiovascular disease [77, 78]

Limited or controversial evidence

Increased risk for sudden infant death [6]

Prematurity [2]

Long-term reduction in lung function in adults $[6,45,46]$

Increased risk for nonrespiratory cancers and childhood leukemia $[2,5]$ 
outcomes. Exposure assessment needs for health effect studies also differ depending on whether the aim is qualitative testing for an association between exposure and a health outcome, or quantitative estimation of effects of given exposure levels. Large study samples with less precise exposure estimates are usually preferable for qualitative studies, whereas accuracy and precision of exposure estimates are more relevant in quantitative studies [20].

Personal monitoring of relevant tobacco smoke constituents gives good information on cumulative exposure over relatively short periods. It is the best approach for assessment of personal exposures in studies of shortterm health effects with small study samples, especially if quantitative assessment of exposure-response relation is desired. Stationary monitoring of pollutant concentrations characterizes reasonably well exposure levels in different microenvironments over time, and is suitable for overall monitoring of the presence and amount of ETS in different indoor environments. Such an approach is often suitable for the purposes of risk assessment, development of preventive strategies, and follow-up of effectiveness of risk management measures. When combined with time-activity data, stationary monitoring can also be used to assess an individual's exposure in studies of relatively short-term health effects.

For studies of health outcomes with a long latency

Table 4. - Guide to the selection of the best approach for assessing exposure to environmental tobacco smoke (ETS)

\section{Personal monitoring of tobacco smoke components (nico-} tine or RSP)

The best method to assess an individual's cumulative ETS exposure in studies of short-term health effects with small study samples

Especially suitable if quantitative assessment of exposureresponse relations is desired

Stationary measurements of indoor air tobacco smoke constituents

Suitable for overall monitoring of the presence and amount of ETS in different microenvironments over time

Suitable for the purposes of risk assessment, development of preventive strategies, and follow-up of risk management measures

When combined with individual time-activity information, can be used to assess an individual's exposure in studies of relatively short-term health effects

\section{Questionnaires and interviews}

Suitable for studies of health outcomes with a long latency period and for studies of rare diseases requiring large study populations

Standardized questionnaires allow comparisons with other studies

Biomarkers

Cotinine measurements in body fluids are suitable for assessment of cumulative doses over short exposure periods in studies of acute health effects

Hair nicotine concentration can be used to assess an individual's cumulative exposure over 1-2 months

A combination of different assessment methods

Often the best approach if enough resources available, for example a nested study design

Questionnaires used to assess ETS exposure in a large study population

More precise exposure information obtained with other methods, e.g. personal monitoring or hair nicotine, in a subsample of the population

RSP: respirable suspended particles. period and for studies of rare diseases requiring large study populations, the only feasible method of ETS exposure assessment is questionnaire-derived information. Use of standardized questionnaires allows comparison with other studies, but it is always important to take into account also the specific needs of the study. Cotinine measurements in body fluids are suitable for assessment of cumulative doses over short exposure periods, and can be used in studies of acute health effects. Hair nicotine is a new biomarker for use in assessing exposure over longer time periods.

A combination of different assessment methods is often the best choice, if the resources are available. According to a nested exposure assessment strategy, questionnaires are used to acquire an indicator of exposure on a large study population, while simultaneously obtaining more precise exposure information with other methods, such as personal monitoring or hair nicotine, in a subsample of the population $[12,15]$. Methods for correcting misclassification of questionnaire-based exposure assessment, utilizing a substudy with more valid and precise exposure estimates, have been developed [20].

In this paper, emphasis has been placed on the complexity of assessing the relevant aspects of exposure to ETS in any given study, and different available assessment methods have been discussed with reference to these issues. Table 4 summarizes the guidelines for selection of the best approach to assess ETS exposure.

Acknowledgement: The authors would like to thank M.R. Becklake for her valuable comments on the manuscript.

\section{References}

1. Friedman GD, Petitti DB, Bawol RD. Prevalence and correlates of passive smoking. Am J Public Health 1983; 73: 401-405.

2. Spitzer WO, Lawrence V, Dales R, et al. Links between passive smoking and disease: a best-evidence synthesis. A report of the Working Group on Passive Smoking. Clin Invest Med 1990; 13: 17-42.

3. Cummings KM, Markello SJ, Mahoney M, Bhargava AK, McElroy PD, Marshall JR. Measurement of current exposure to environmental tobacco smoke. Arch Environ Health 1990; 45: 74-79.

4. Riboli E, Preston-Martin S, Saracci R, et al. Exposure of nonsmoking women to environmental tobacco smoke: a 10-country collaborative study. Cancer Causes Control 1990; 1: 243-252.

5. Samet JM, Cain WS, Leaderer BP. Environmental tobacco smoke. In: Samet JM, Spengler JD, eds. Indoor Air Pollution: A Health Perspective. Baltimore, The Johns Hopkins University Press, 1991; pp. 131-169.

6. US Environmental Protection Agency. Respiratory health effects of passive smoking: lung cancer and other disorders. Washington DC, US Environmental Protection Agency, Office of Health and Environmental Assessment, Office of Research and Development. 1992; EPA/600/690/006F.

7. Emmons KM, Abrams DB, Marshall R, et al. An evaluation of the relationship between self-report and biochemical measures of environmental tobacco smoke exposure. Prev Med 1994; 23: 35-39.

8. Nafstad P, Botten G, Hagen JA, et al. Comparison of three methods for estimating environmental tobacco smoke exposure among children aged between 12 and 36 months. Int J Epidemiol 1995; 24: 88-94. 
9. Ryan PB, Lambert WE. Personal exposure to indoor air pollution. In: Samet JM, Spengler JD, eds. Indoor Air Pollution: A Health Perspective. Baltimore, The Johns Hopkins University Press, 1991; pp. 109-127.

10. Ott WR. Total human exposure. Environ Sci Technol 1985; 19: 880-886.

11. Ott WR. Human exposure assessment: the birth of a new science. J Exp Anal Environ Epidemiol 1995; 5: 449-472.

12. National Research Council, Committee on Advantages in Assessing Human Exposure to Airborne Pollutants. Human exposure assessment to airborne pollutants: advantages and opportunities. Washington DC, National Academy Press, 1991.

13. Lebowitz MD. Exposure assessment needs in studies of acute health effects. Sci Total Environ 1995; 168: 109-117.

14. US Department of Health and Human Services. The health consequences of smoking: chronic obstructive pulmonary disease. A report of the Surgeon General. Washington DC, US Department of Health and Human Services, Public Health Service, Office of the Assistant Secretary for Health, Office of Smoking and Health, 1984; DHHS Publication No. 84-50205.

15. Leaderer BP, Lioy PJ, Spengler JD. Assessing exposures to inhaled complex mixtures. Environ Health Perspect 1993; 101 (Suppl. 4): 167-177.

16. Leaderer B. Assessing exposure to environmental tobacco smoke. Risk Anal 1990; 10(1): 19-26.

17. Last JM. A Dictionary of Epidemiology. New York, Oxford University Press, 1983.

18. Seifert B. Validity criteria for exposure assessment methods. Sci Total Environ 1995; 168: 101-107.

19. Schulte P, Mazzuckelli LF. Validation of biological markers for quantitative risk assessment. Environ Health Perspect 1991; 90: 239-246.

20. Armstrong B. Study design for exposure assessment in epidemiological studies. Sci Total Environ 1995; 168: 187-194.

21. Wallace LA, Ott WR. Personal monitors: a state-of-theart survey. J Air Poll Control Ass 1982; 32: 601-610.

22. Hammond SK, Leaderer BP. A diffusion monitor to measure exposure to passive smoking. Environ Sci Technol 1987; 21: 494-497.

23. Hammond SK, Leaderer BP, Roche AC, Schenker M. Collection and analysis of nicotine as a marker for environmental tobacco smoke. Atmos Environ 1987; 21: 457-462.

24. Henderson FW, Reid HF, Morris R, et al. Home air nicotine levels and urinary cotinine excretion in preschool children. Am Rev Respir Dis 1989; 140: 197-201.

25. Turner WA, Spengler JD, Dockery DW, Colome SD. Design and performance of a reliable personal monitoring system for respirable particulates. J Air Poll Control Ass 1979; 29: 747-749.

26. McCarthy JF, Bearg DW, Spengler JD. Assessment of indoor air quality. In: Samet JM, Spengler JD, eds. Indoor Air Pollution: A Health Perspective. Baltimore, The Johns Hopkins University Press, 1991; pp. 82-108.

27. Spengler JD, Treitman RD, Tosteson TD, Mage DT, Soczek ML. Personal exposures to respirable particulates and implications for air pollution epidemiology. Environ Sci Technol 1985; 19: 700-707.

28. Coghlin J, Hammond SK, Gann PH. Development of epidemiologic tools for measuring environmental tobacco smoke exposure. Am J Epidemiol 1989; 130: 696-704.

29. Spengler JD, Dockery DW, Turner WA, Wolfson JM, Ferris BG. Long-term measurements of respirable sulfates and particles inside and outside homes. Atmos Environ 1981; 15: 23-30.
30. Leaderer BP, Hammond SK. Evaluation of vapourphase nicotine and respirable suspended particle mass as markers for environmental tobacco smoke. Environ Sci Technol 1991; 25: 770-777.

31. Marbury MC, Hammond SK, Haley NJ. Measuring exposure to environmental tobacco smoke in studies of acute health effects. Am J Epidemiol 1993; 137: 1089-1097.

32. Emerson JA, Hovell MF, Meltzer SB, et al. The accuracy of environmental tobacco smoke exposure measures among asthmatic children. J Clin Epidemiol 1995; 48: 1251-1259.

33. Muramatsu M, Umemura S, Okada T, Tomia H. Estimation of personal exposure to tobacco smoke with a newly developed nicotine personal monitor. Environ Res 1984; 35: 218-227.

34. Miesner EA, Rudnick SN, Hu F, et al. Particle and nicotine sampling in public facilities and offices. J Air Poll Control Ass 1989; 39: 1577-1582.

35. Thompson CV, Jenkins RA, Higgins CE. A thermal desorption method for the determination of nicotine in indoor environments. Environ Sci Technol 1989; 23: 429-435.

36. Coultas DB, Samet JM, McCarthy JF, Spengler JD. Variability of measures of exposure to environmental tobacco smoke in the home. Am Rev Respir Dis 1990; 142: 602-606.

37. Delfino RJ, Ernst P, Jaakkola MS, Solomon S, Becklake MR. Questionnaire assessments of recent exposure to environmental tobacco smoke in relation to salivary cotinine. Eur Respir J 1993; 6: 1104-1108.

38. Jarvis MJ, Russel MAH, Feyerabend C, et al. Passive exposure to tobacco smoke: saliva cotinine concentrations in a representative population sample of nonsmoking schoolchildren. Br Med J 1985; 291: 927-929.

39. O'Connor TZ, Holford TR, Leaderer BP, Hammond SK, Bracken MB. Measurement of exposure to environmental tobacco smoke in pregnant women. Am J Epidemiol 1995; 142: 1315-1321.

40. Nafstad P, Jaakkola JJK, Hagen JA, Zahlsen K, Magnus $\mathrm{P}$. Hair nicotine concentrations in mothers and children in relation to parental smoking. J Exp Anal Environ Epidemiol 1997; 7: 235-239.

41. Pron GE, Burch JD, Howe GR, Miller AB. The reliability of passive smoking histories reported in a casecontrol study of lung cancer. Am J Epidemiol 1988; 127: 267-273.

42. Coultas DB, Peake GT, Samet JM. Questionnaire assessment of lifetime and recent exposure to environmental tobacco smoke. Am J Epidemiol 1989; 130: 338-347.

43. Cummings KM, Markello SJ, Mahoney MC, Marshall JR. Measurement of lifetime exposure to passive smoke. Am J Epidemiol 1989; 130: 122-132.

44. Masi MA, Hanley JA, Ernst P, Becklake MR. Environmental tobacco smoke and lung function in young adults. Am Rev Respir Dis 1988; 138: 296-299.

45. Jaakkola MS. The role of active and passive smoking in the evolution of ventilatory lung function and respiratory symptoms during young adulthood. An eight-year cohort study. Academic Dissertation. Helsinki, Helsinki University Printing House, 1994; pp. 1-234.

46. Jaakkola MS, Jaakkola JJK, Becklake MR, Ernst P. Passive smoking and evolution of lung function in young adults. An eight-year longitudinal study. J Clin Epidemiol 1995; 48: 317-327.

47. Jaakkola MS, Jaakkola JJK, Becklake MR, Ernst P. Effect of passive smoking on the development of respiratory symptoms in young adults. An eight-year longitudinal study. J Clin Epidemiol 1996; 49: 581-586.

48. Lebowitz MD, Quackenboss JJ, Soczek ML, Kollander 
$\mathrm{M}$, Colome S. The new standard environmental inventory questionnaire for estimation of indoor concentrations. J Air Pollut Control Assoc 1989; 39: 1411-1419.

49. Robinson JP. Time-diary research and human exposure assessment: some methodological considerations. Atmos Environ 1988; 22: 2085-2092.

50. Waldman JM, Bilder SM, Freeman NCG, Friedman M. A portable datalogger to evaluate recall-based time-use measures. J Expo Anal Environ Epidemiol 1993; 3: 39-48.

51. National Research Council. Biologic markers of pulmonary toxicology. Washington DC, National Academy Press, 1989.

52. Idle JR. Titrating exposure to tobacco smoke using cotinine - a minefield of misunderstandings. J Clin Epidemiol 1990; 43: 313-317.

53. Sheen SJ. Detection of nicotine in foods and plant materials. J Food Sci 1988; 53: 1572-1573.

54. Davis RA, Stiles MF, DeBethizy JD, Reynolds JH. Dietary nicotine: a source of urinary cotinine. Food Chem Toxicol 1991; 29: 821-827.

55. Tunstall-Pedoe H, Woodward M, Brown CA. Tea drinking, passive smoking, smoking deception and serum cotinine in the Scottish heart health study. J Clin Epidemiol 1991; 44: 1411-1414.

56. Langone JJ, Gjika HB, Van Vunakis H. Nicotine and its metabolites. Radioimmunoassays for nicotine and cotinine. Biochemistry 1973; 12: 5025-5030.

57. Collier AM, Goldstein GM, Shrewsbury RP, Zhang CA, Williams RW. Urine cotinine elimination half-life in young children exposed to sidestream cigarette smoke. In: Indoor Air '90. Proceedings of the 5th International Conference on Indoor Air Quality and Climate. Vol. 2. Characteristics of Indoor Air. Ottawa, Canada Mortgage and Housing Corporation, 1990; pp. 195-200.

58. Watts RR, Langone JJ, Knight GJ, Lewtas J. Cotinine analytical workshop report: consideration of analytical methods for determining cotinine in human body fluids as a measure of passive exposure to tobacco smoke. Environ Health Perspect 1990; 84: 173-182.

59. Bjercke RJ, Cook G, Rychlik N, Gjika HB, Van Vunakis $\mathrm{H}$, Langone JJ. Stereospecific monoclonal antibodies to nicotine and cotinine and their use in enzyme-linked immunosorbent assays. J Immunol Methods 1986; 90: 203-213.

60. Feyerabend C, Russell MAH. A rapid gas-liquid chromatographic determination of cotinine in biological fluids. Analyst 1980; 105: 993-1001.

61. Curvall M, Kazemi-Vala E, Enzell CR. Simultaneous determination of nicotine and cotinine in plasma using capillary column gas chromatography with nitrogensensitive detection. J Chromatogr Biomed Appl 1982; 232: 283-293.

62. Daenens P, Laruelle L, Callewaert K, DeSchepper P, Galeazzi R, Van Rossum J. Determination of cotinine in biological fluids by capillary gas chromatographymass spectrometry-selected ion monitoring. J Chromatogr Biomed Appl 1985; 342: 79-87.

63. Etzel RA. A review of the use of saliva cotinine as a marker of tobacco smoke exposure. Prev Med 1990; 19: 190-197.

64. Poppe WA, Peeters R, Daenens P, Ide PS, Van Assche FA. Tobacco smoking and the uterine cervix: cotinine in blood, urine and cervical fluid. Gynecol Obstet Invest 1995; 39: 110-114.

65. Pacifici R, Altieri I, Gandini L, et al. Environmental tobacco smoke: nicotine and cotinine concentration in semen. Environ Res 1995; 68: 69-72.
66. Jarvis MJ, Russell AJ. Measurement and estimation of smoke dosage to non-smokers from environmental tobacco smoke. Eur J Respir Dis 1984; 65 (Suppl. 133): $68-75$.

67. Greenberg RA, Haley NJ, Etzel RA, Loda FA. Measuring the exposure of infants to tobacco smoke. Nicotine and cotinine in urine and saliva. $N$ Engl J Med 1984; 310: 1075-1078.

68. Nafstad P, Kongerud J, Botten G, et al. Fetal exposure to tobacco smoke products: A comparison between selfreported maternal smoking and concentrations of cotinine and thiocyanate in cord serum. Acta Obstet Gynecol Scand 1996; 75: 902-907.

69. Jarvis MJ. Application of biochemical intake markers to passive smoking measurement and risk estimation. Mutat Res 1989; 222: 101-110.

70. Zahlsen K, Nilsen OG. Gas chromatographic analysis of nicotine in hair. Environ Technol 1990; 11: 353364.

71. Nilsen T, Zahlsen K, Nilsen OG. Uptake of nicotine in hair during controlled environmental air exposure to nicotine vapour: evidence for a major contribution of environmental nicotine to the overall nicotine found in hair from smokers and non-smokers. Pharmacol Toxicol 1994; 75: $136-142$.

72. Hammond SK, Coghlin J, Gann PH, et al. Relationship between environmental tobacco smoke exposure and carcinogen-hemoglobin adduct levels in nonsmokers. $J$ Natl Cancer Inst 1993; 85: 474-478.

73. Samet JM, Marbury MC, Spengler JD. Health effects and sources of indoor air pollution. Part I. Am Rev Respir Dis 1987; 136: 1486-1508.

74. Tredaniel J, Boffetta P, Saracci R, Hirsch A. Exposure to environmental tobacco smoke and adult non-neoplastic respiratory diseases. Eur Respir J 1994; 7: 173-185.

75. Tredaniel J, Boffetta P, Saracci R, Hirsch A. Exposure to environmental tobacco smoke and risk of lung cancer: the epidemiological evidence. Eur Respir J 1994; 7: $1877-1888$.

76. US Department of Health and Human Services. The health consequences of involuntary smoking. A report of the Surgeon General. Washington DC, US Department of Health and Human Services, Public Health Service, Centers for Disease Control, Center for Health Promotion and Education, Office on Smoking and Health, 1986; DHHS Publication No. (CDC) 87-8398.

77. Glantz SA, Parmley WW. Passive smoking and heart disease. Circulation 1991; 83: 1-12.

78. Taylor AE, Johnson DC, Kazemi H. Environmental tobacco smoke and cardiovascular disease. A position paper from the Council on Cardiopulmonary and Critical Care, American Heart Association. Circulation 1992; 86: 699-702.

79. Kramer MS. Determinants of low birth weight: methodological assessment and meta-analysis. Bull WHO 1987; 65: 663-737.

80. Schwartz J, Zeger S. Passive smoking, air pollution, and acute respiratory symptoms in a diary study of student nurses. Am Rev Respir Dis 1990; 141: 62-67.

81. Nafstad P, Kongerud J, Botten G, Hagen JA, Jaakkola JJK. The role of passive smoking in the development of bronchial obstruction during the first 2 years of life. Epidemiology 1997; 8: 293-297.

82. Leuenberger P, Schwartz J, Ackermann-Liebrich U, et al. Passive smoking exposure in adults and chronic respiratory symptoms (SAPALDIA study). Am J Respir Crit Care Med 1994; 150: 1222-1228. 